\title{
Fitorremediação como solução para solos contaminados por metais pesados
}

\section{Phytoremediation as a solution for soils contaminated by heavy metals}

\author{
Maria Alexandra Estrela ${ }^{1}$, Lúcia Helena Garofalo Chaves ${ }^{2}$,
} Larissa Novais Silva ${ }^{3}$

\begin{abstract}
RESUMO: Inúmeras técnicas têm sido trabalhadas no sentido de diminuir os impactos ambientais causados pelas atividades econômicas que lançam no ambiente poluentes de natureza diversa. Conhecer mecanismo como a Fitorremediação é de grande importância técnica e científica de maneira que se trata de uma tecnologia verde e de baixo custo. No entanto, tal técnica ainda é pouco conhecida no Brasil. Porém, por tratar-se de uma tecnologia de baixo custo e de rápido desempenho, é necessário conhecer o potencial das espécies e, com isso, testá-las quanto a sua aptidão como fitoextratoras, para com isso determinar um determinado número de plantas com potencial para auxiliar na restauração de áreas degradadas por metais pesados.
\end{abstract}

PALAVRAS -CHAVE: Tecnologia; Verde; Remediação.

\begin{abstract}
Numerous techniques have been worked on feeling to reduce the environmental impacts of economic activities they put on the diverse nature of environment pollutants. Knowing mechanism as Phytoremediation is of great importance for technical and scientific way that it is a green technology and low cost. However this technique is still little known in Brazil. However because it is a low cost and fast performance technology it is necessary to know the potential of this species and test them as to their suitability as fitoextratoras for it to determine a certain number of plants with the potential to help restore of degraded areas by heavy metals.
\end{abstract}

KEYWORDS: Technology; Green; Remediation.

1. Graduada em Agronomia pela Universidade Federal da Paraíba, Mestre em Engenharia Agrícola pela Universidade Federal de Campina Grande, Especialista em Educação. Professora e coordenadora na Universidade Ceuma, campus Imperatriz-MA.

E-mail: alexandraestrela@ hotmail.com

2. Graduada em Agronomia pela Escola Superior de Agricultura Luiz de Queiroz, Mestre em Agronomia pela Escola Superior de Agricultura Luiz de Queiroz e Doutora em Agronomia pela Escola Superior de Agricultura Luiz de Queiroz. Atualmente é professora titular da Universidade Federal de Campina Grande. E-mail: luciahg@ hotmail.com

3. Acadêmica do $4^{\circ}$ período do curso de Arquitetura e Urbanismo da Universidade Ceuma, campus Imperatriz. 


\section{Introdução}

A elevação do número de atividades industriais e de mineração aliados ao uso inadequado de fertilizantes e pesticidas têm contribuído para a contaminação do solo, cursos de água e lençol freático por metais pesados. Os valores de contaminação do solo por metais pesados são diferenciados para área agrícola, residencial e industrial.

Uma determinada área é considerada contaminada se, entre outros fatores, as concentrações de elementos ou substâncias de interesse ambiental estão acima de um dado limite denominado valor de intervenção. Acima desse limite, há um risco potencial de efeito deletério sobre a saúde humana, havendo necessidade de uma ação imediata na área (CETESB, 1999).

A descontaminação de uma área pode ser realizada por diversos métodos como a escavação do solo, uso de microrganismos, extração "in situ", vitrificação, entre outras, porém algumas dessas técnicas requerem muito tempo de execução, efeito visual e demanda de altos custos para efetivação do processo.

$\mathrm{Na}$ busca de alternativas para despoluir áreas contaminadas por diferentes compostos, procuram-se identificar técnicas que apresentem eficiência na descontaminação, simplicidade na execução, menor tempo demandado pelo processo e menor custo (PIRES et al., 2003ab).

Dessa forma, a busca e o desenvolvimento de soluções tecnológicas que atendam à legislação ambiental se fazem primordial. Neste contexto, destaca-se a fitorremediação uma técnica que emprega plantas com o objetivo de remover, transferir, estabilizar ou destruir elementos nocivos. A sua classificação depende da técnica a ser empregada, da natureza química, ou das propriedades do poluente. As plantas podem remediar os solos contaminados através dos seguintes mecanismos: fitoextração, fitoestabilização, rizofiltração, fitodegradação, fitoestimulação, fitovolatização, cepas vegetativas, açudes artificiais e barreiras hidráulicas (BURKEN, 2002).

A Fitoextração utiliza plantas para remover os metais do solo, acumulandoos nas raízes e parte aérea. É uma tecnologia de baixo custo (TANDY et al., 2004) e o seu sucesso dependerá do grau de contaminação do metal no solo, da capacidade das plantas em acumularem o metal na parte aérea e da disponibilidade do metal no 
solo (ERNEST, 1996). Essa técnica possui outros benefícios como a manutenção da fertilidade do solo e a grande aceitação pública por ser uma tecnologia 'verde', além de ter a luz solar como principal fonte de energia (USEPA 2004; PEREIRA, 2005).

O estudo e a exploração comercial de plantas fitoextratoras estão bastante avançados nos países desenvolvidos e com políticas ambientais bem definidas. No Brasil, porém, essa técnica é pouco explorada por falta de capacitação técnica, desconhecimento do mercado e pelo fato de as plantas hiperacumuladoras conhecidas serem, em sua maioria, de clima temperado (PEREIRA, 2005).

Deste modo, objetivou-se, através de revisão de literatura, identificar e caracterizar a Fitorremediação como meio de mitigação de impactos ambientais em áreas contaminadas por metais pesado.

\section{Revisão de Literatura}

\subsection{Aspectos gerais da Fitorremediação}

Atualmente, um dos problemas mais sérios que afetam o meio ambiente é a poluição química de natureza orgânica ou inorgânica, decorrente dos despejos residenciais e industriais, mineração e uso de agrotóxicos na agricultura. Define-se como poluição qualquer alteração física, química ou biológica que produza modificação no ciclo biológico normal, interferindo na composição da fauna e da flora do meio (AGUIAR et al., 2002).

Penkov (1991) cita que aumentos nos teores naturais de metais pesados podem ocorrer em áreas próximas de complexos industriais, urbanos e, também, nas áreas rurais de agricultura altamente tecnificada. É constatado em tais áreas aumento nos teores de Zinco, Chumbo, Níquel, Cádmio, Cobre, Mercúrio, Arsênio, entre outros.

A contaminação do ambiente ocorre principalmente por metais pesados que, em alguns casos, são substâncias altamente tóxicas e não são compatíveis com a maioria dos tratamentos biológicos de efluentes existentes. Dessa forma, efluentes contendo esses metais não devem ser descartados na rede pública, para tratamento em conjunto com o esgoto doméstico. No entanto as principais fontes de poluição por metais pesados ainda são provenientes dos efluentes industriais, de mineração e das lavouras (AGUIAR et al., 2002). 
$\mathrm{Na}$ busca pela recuperação de solos poluídos por metais pesados, várias técnicas têm sido utilizadas como escavação e substituição do solo ou tratamento químico "ex situ”, que têm sido eficazes em pequenas áreas. Porém, essas técnicas são de alto custo e causam grande impacto visual no meio. A fitorremediação, que utiliza plantas para remediar solos poluídos, tem sido sugerida como alternativa viável às técnicas tradicionais em razão dos menores custos e da maior aceitação pelo público.

A fitoextração, que é uma das técnicas mais eficientes de fitorremediação, envolve o cultivo de plantas que concentram metais pesados do solo na parte aérea, a qual pode então ser removida da área. O sucesso da fitoextração dependerá da habilidade das plantas em acumular concentrações de metais pesados na parte aérea que sejam suficientemente elevadas para reduzir a concentração de metais no solo em níveis toleráveis, com poucos cultivos (MELO et al, 2006).

\subsection{Metais pesados como contaminantes do solo}

Metais pesados (MP) são definidos como elementos com densidade relativa maior que $5 \mathrm{~g} / \mathrm{cm}^{-3}$, ou número atômico maior que 20, incluindo-se metais, semimetais e não metais, estes estão presentes em rochas e em áreas com adição de rejeitos industriais, biossólidos e alguns agroquímicos em grandes quantidades. Alguns desses elementos são essenciais para várias funções fisiológicas nos seres vivos, como $\mathrm{Fe}, \mathrm{Cu}, \mathrm{Zn}$ e $\mathrm{Mn}$. Quando se encontram em excesso no solo, esses elementos podem inibir o crescimento das plantas e causar alterações nas comunidades vegetais, como também exercer efeitos adversos sobre os microrganismos do solo, interferindo nas funções do ecossistema, com consequências ao meio ambiente e à saúde pública (CARNEIRO et. al., 2001). Os principais metais pesados presentes no solo e nos produtos utilizados na agricultura são $\mathrm{Co}, \mathrm{Cd}, \mathrm{Cr}, \mathrm{Cu}, \mathrm{Fe}, \mathrm{Hg}, \mathrm{Mn}, \mathrm{Ni}, \mathrm{Pb}, \mathrm{Sn}$ e Zn (ABREU et al., 2002).

Estes ocorrem naturalmente na crosta terrestre, constituindo menos de $1 \%$ das rochas. Quanto à origem, podem ser litogênicos quando provenientes de fontes geológicas, como resíduos de rocha liberados pelo intemperismo, ou antropogênicos, quando adicionados ao solo pela atividade humana, via mineração e aplicação de defensivos agrícolas e fertilizantes (CAMARGO et al., 2001). Através da absorção destes pelas plantas, os metais podem entrar na cadeia trófica, contaminando homem 
e animais (ACCIOLY \& SIQUEIRA, 2000). Apresentam ainda, elevada persistência no solo, por causa da sua baixa mobilidade (FREITAS, 2008).

Dos metais pesados, os mais relevantes devido à toxicidade, danos à agricultura e à saúde humana são: o arsênio (As), o cádmio $(\mathrm{Cd})$, o mercúrio $(\mathrm{Hg}), \mathrm{o}$ chumbo (Pb), o tálio (Tl) e o urânio (U) (GABOS, 2008).

Esses elementos podem expressar seu potencial poluente diretamente nos organismos do solo, pela disponibilidade às plantas em níveis fitotóxicos, além da possibilidade de transferência para a cadeia alimentar através das próprias plantas ou pela contaminação das águas de superfície e subsuperfície (OLIVEIRA \& MATTIAZO, 2001).

A concentração de elementos químicos nas plantas dependerá da interação de alguns fatores como solo, espécie vegetal, estádio de maturação, rendimento, manejo da cultura e clima. Mas, o principal fator é o potencial de absorção, específico e geneticamente fixado para os diferentes nutrientes e diferentes espécies vegetais. Além disso, o acúmulo de metais pesados é também muito variável de um determinado órgão para outro da planta (ANJOS \& MATTIAZZO, 2001).

A presença destes no solo se deve em grande parte ao uso de agroquímico no solo e nas culturas. Seja na forma de fertilizante ou inseticida, essa prática, no entanto, pode causar degradação química no solo com o acumulo de elementos tóxicos. Alguns estudos já mostraram a incidência de metais pesados, como impurezas de fertilizantes e inseticidas aplicados aos solos agrícolas, os principais elementos encontrados foram $\mathrm{Mn}, \mathrm{Zn}, \mathrm{Co}$ e $\mathrm{Pb}$. O Zn é frequentemente o principal componente das impurezas dos fertilizantes minerais e orgânicos e também corretivos, sendo encontrado em alguns inseticidas em porcentagens de até $25 \%$ (RAMALHO et al, 2000).

Estudos revelam que o impacto ambiental causado pelos metais no solo vem crescendo, principalmente quando se trata do chumbo (PEDRAZZOLI, 2004). A figura 1 mostra a ocorrência dos contaminantes mais comuns do solo (EPA, 1997): 
Figura 1: Contaminantes mais comuns nos solos

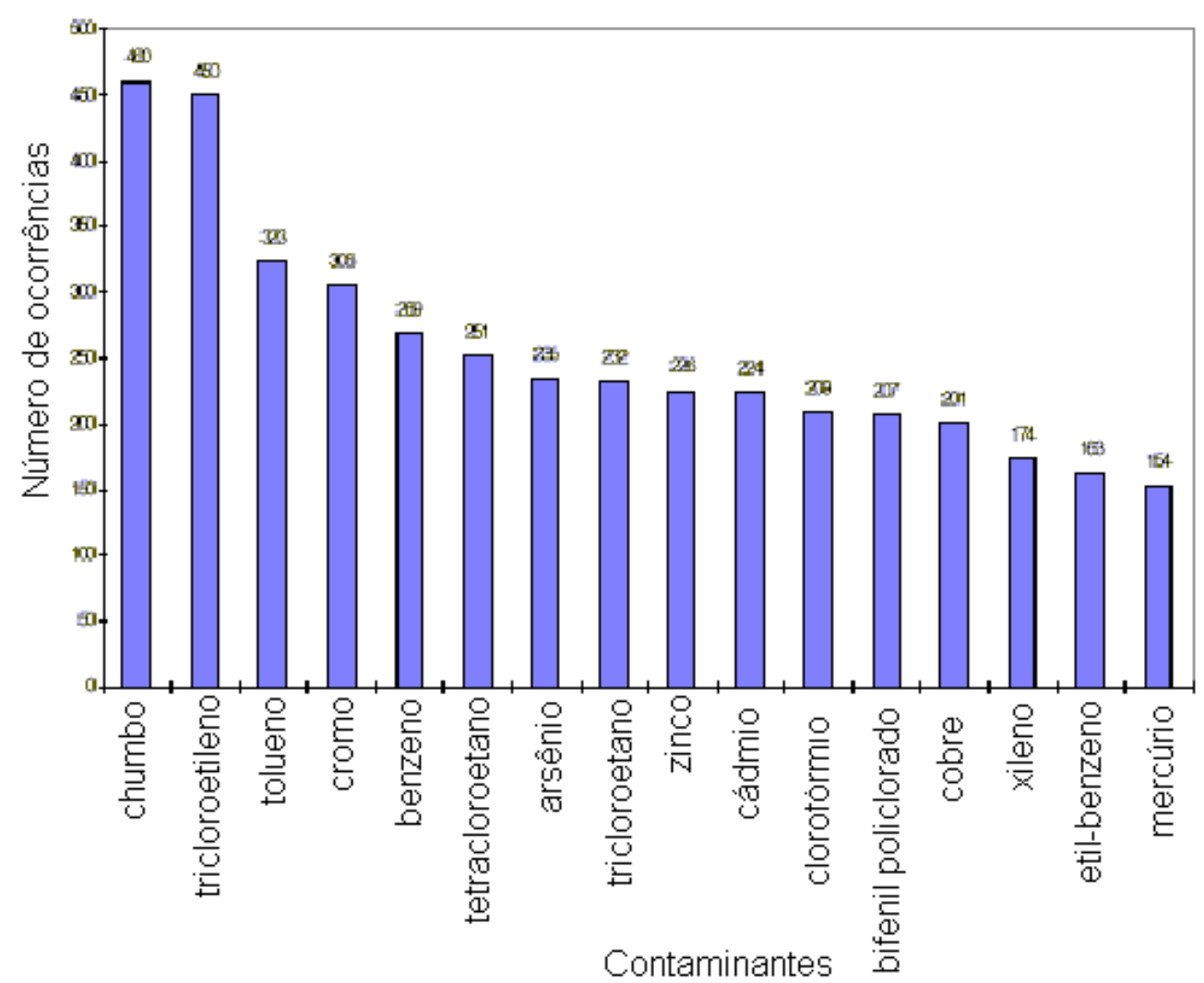

Fonte: EPA (1997).

\subsection{Tratamento de solos contaminados por metais pesados}

A contaminação por metais é um problema comum em locais onde existe a ocorrência de resíduos perigosos, os quais podem ser tratados, a princípio, por algumas tecnologias conhecidas: Transporte no solo; Solidificação/estabilização; Remediação eletrocinética; Fitorremediação (PEDRAZZOLI, 2004).

Para uma comparação destas tecnologias definem-se fatores como: o estado da arte, a ordem dos metais tratados, o maior fator limitante, e considerações específicas do local. O estado da arte refere-se à fase de desenvolvimento da tecnologia. A ordem dos metais tratados está relacionada à quantidade de metais tratados pela tecnologia. O fator limitante refere-se a questões gerais que podem interferir no uso da tecnologia, tais como: tempo para remover o metal do solo e estado da arte. As considerações específicas do local referem-se às características de solo e de profundidade dos contaminantes que podem influenciar na eficiência da tecnologia aplicada (PEDRAZZOLI, 2004). 
Em termos globais, podem distinguir-se duas grandes linhas de processos de descontaminação de solos (SEPÚLVEDA \& RIBEIRO, 1994; NAZAROFF \& ALVAREZ-DOHEN, 2001; CORREIA 2002): In-situ: a operação de descontaminação dá-se no local onde se encontra o terreno a regenerar, sendo os contaminantes retirados do solo através de meios de transporte como a água e/ou o ar. Estes veículos de transporte são então tratados. Quer por via química, biológica ou Mecânica e novamente introduzidos no terreno. Ex-situ: este tipo de operação implica a remoção do solo do local onde este se encontra inicialmente, de modo a ser submetido a tratamento de descontaminação. Os tratamentos ex-situ podem ser onsite, quando ocorrem diretamente no local (por exemplo, através de uma unidade de lavagem de solos) ou off-site quando o tratamento implica o transporte do solo contaminado até à central de tratamento, onde sofre determinados processos de descontaminação. As principais técnicas de remediação de solo estão descritas no quadro abaixo:

Figura 2: Métodos e técnicas de tratamento de solos contaminados

\begin{tabular}{|c|c|c|c|}
\hline \multicolumn{2}{|c|}{ Métodos } & "In-situ" & "On/off-site" \\
\hline \multicolumn{2}{|l|}{ térmicos } & (sem aplicaçdo) & combustăo \\
\hline \multirow{2}{*}{ físico-químicos } & seco & injecçăo de ar & dessortaçăo em reactor \\
\hline & hámido & $\begin{array}{l}\text { lavagem do solo } \\
\text { extracção }\end{array}$ & $\begin{array}{l}\text { lavagem do solo } \\
\text { extracçăo }\end{array}$ \\
\hline \multicolumn{2}{|l|}{ biológicos } & biologgicos & $\begin{array}{l}\text { "landfarming" } \\
\text { bioreactor }\end{array}$ \\
\hline \multicolumn{2}{|c|}{ processos especiais } & $\begin{array}{l}\text { p. ex: vitrificaçà̃o } \\
\text { electrocinéticos }\end{array}$ & $\begin{array}{l}\text { p. } 6 x: \\
\text { electrocinéticos }\end{array}$ \\
\hline \multicolumn{2}{|l|}{ isolamento } & confinamento & (sem aplicagäo) \\
\hline
\end{tabular}

Fonte: adaptado de MOLITOR (1991). 


\subsection{Fitoextração como medida de descontaminação de solos contaminados por metais}

A tecnologia de fitorremediação encontra-se num estágio de comercialização para tratamento de solos contaminados com metais sendo que, em um futuro próximo, poderá proporcionar uma opção de baixo custo sob circunstâncias específicas. Esta tecnologia tende a adaptar-se melhor para remediação de locais com contaminação dispersa, baixas concentrações de contaminantes e também estes devem estar localizados na superfície dos solos (PEDRAZZOLI, 2004).

A utilização de plantas para a recuperação de áreas contaminadas, técnica conhecida como fitorremediação, tem se popularizado e surgido como alternativa viável, uma vez que é considerada de baixo custo, promove a manutenção da fertilidade do solo, além de ter como principal fonte de energia a luz solar (ROBINSON et al., 2003).

Os principais mecanismos da fitorremediação são: absorção e acumulação dos metais pesados nos tecidos das plantas (fitoextração); adsorção dos metais no sistema radicular, imobilizando os contaminantes (fito adsorção); libertação para o solo de oxigênio e outros compostos, que podem imobilizar os metais pesados (fito estabilização); estimulação da biorremediação por fungos ou outros microrganismos localizados no sistema solo-raiz (rizo remediação).

Dentre esses mecanismos existem dois processos básicos de fitorremediação de metais: fitoextração e fito estabilização. A fitoextração ocorre no transporte de contaminantes do solo para um tecido vegetal sobre o solo e sua destruição posterior. Embora a alta taxa de acúmulo de metais em árvores, arbustos, ervas, gramas e sementes apresentarem certo potencial, as sementes parecem ser o elemento mais promissor, uma vez que sua biomassa apresenta maior produção. Níquel e zinco parecem ser mais facilmente absorvidos embora testes preliminares com cobre e cádmio sejam estimulados. O chumbo não tem tido resultado positivo em plantas testadas até agora. Entretanto, há pesquisas indicando que a utilização de solos modificados facilitaria a incorporação do chumbo em plantas (PEDRAZZOLI, 2004). 
A fitoextração é a técnica mais promissora da Fitorremediação, tendo despertado maior atenção dos pesquisadores, desde que foi proposta por Chaney (1983) como uma tecnologia para recuperar solos poluídos por metais. O processo de fitoextração de metais do solo dependerá da habilidade das plantas selecionadas crescerem e acumularem metais sob as condições climáticas e de solo específicas da área a ser remediada. Duas abordagens têm sido usadas para atingir esta meta: o uso de plantas com excepcional capacidade natural de acumulação de metal, as chamadas hiperacumuladoras; no entanto, uma característica geral dessas espécies é o crescimento lento e a limitada produção de biomassa. Outra estratégia é a utilização de plantas cultivadas de alta produção de biomassa, a exemplo de milho (Zea mays) e mostarda da Índia (Brassica juncea), associadas a um método de fitoextração induzida por agentes quelantes (FREITAS, 2008).

A eficiência da Fitorremediação dependerá das características do solo, do contaminante em questão e da planta. A área a ser tratada por meio da Fitorremediação deverá ser propícia ao crescimento de plantas e o elemento no solo deve estar em formas disponíveis para a absorção pelas raízes. A planta usada no processo de Fitorremediação deve ser não apenas tolerante ao contaminante, mas também capaz de absorver e acumular grandes quantidades do mesmo em sua biomassa. A produção de biomassa na parte aérea é outro atributo importante a ser considerado. Infelizmente, a maioria das plantas identificadas como hiperacumuladoras de metais possui uma baixa produção de biomassa (GONZAGA et al, 2008).

Algumas plantas são eficientes no que diz respeito à acumulação de metais, tais como: mostarda (Brassica hirta), girassol (Helianthus annuus), milho (Zea mays), amendoim (Arachis hypogaea), brócolis (Brassica oleracea), trigo mourisco (Fagopyrum esculentum Moench), capim vetiver ou de cheiro (Chrysopogon zizanioides (L.) Roberty), entre outras (MARQUES, 2009).

A literatura científica tem demonstrado que espécies vegetais apresentam comportamento distinto quanto à forma de absorção, distribuição e acúmulo desse elemento, podendo ocorrer variações mesmo entre variedades de uma mesma espécie, quando submetidas a condições similares de contaminação (MARQUES, 2009). 


\section{Considerações Finais}

Ainda pouco conhecida e também pouco estudada no Brasil, tal técnica é de grande relevância cientifica e tecnológica, visto que as áreas em estado de degradação aumentam gradativamente em razão das diversas atividades econômicas, as quais deixam profundas marcas nos ecossistemas devido ao descarte indevido de poluentes químicos.

Com isto faz-se necessário realizar estudos mais profundos e investimentos tecnológicos na identificação de organismos com potencial fitorremediador para, com isso, contribuirmos para a sustentabilidade ambiental.

\section{REFERÊNCIAS}

ABREU, C. A.; ABREU, M. F.; BERTON, R. S. Análise química de solo para metais pesados. In: Alvarez, V. V. H.; SCHAEFER, C. E. G. R.; BARROS, N. F.; MELlO, J. W. V.; COSTA, L. M. Tópicos em Ciência do Solo. v. 2. Viçosa: Sociedade Brasileira de Ciência do Solo, 2002. p. 645-692.

ACCIOLY, A. M. A. \& SIQUEIRA, J. O. Contaminação química e biorremediação do solo. In: NOVAIS, R. F.; ALVAREZ, V. H. \& SCHAEFER, C. E. G. R. Tópicos em Ciência do Solo. Viçosa: Sociedade Brasileira de Ciência do Solo, 2000. p. 299352.

AGUIAR, M. R. M. P. DE; NOVAES, A. C.; GUARINO, A. W. S. Remoção de metais pesados de efluentes industriais por aluminossilicatos. Revisão. Rio de Janeiro. Química Nova, Vol. 25, No. 6B, 1145-1154, 2002.

ANJOS, A. R. M. dos; MATTIAZZO, M. E. Metais pesados em plantas de milho cultivadas em Latossolos repetidamente tratados com biossólido. Scientia Agrícola, v.57, n.4, p.769-776, out./dez. 2000.

BURKEN, J. B. (2002) - VOCs Fate and Partitioning in Vegetation: Use of Tree Cores in Groundwater Analysis. Environmental Scince Technology, v. 36, n. 21, p. $4663-4668$. 
CAMARGO, O. A.; ALLEONI, L. R. F. \& CASAGRANDE, J. C. Reações dos micronutrientes e elementos tóxicos no solo. In: Ferreira, M. E.; Cruz, M. C. P.; Raij, B. \& Abreu, C. A. Micronutrientes e elementos tóxicos na agricultura. Jaboticabal: Legis Summa, 2001. p. 89-124.

CARNEIRO, M. A. C. C.; SIQUEIRA, J. O.; MOREIRA, F. M. DE S.

Estabelecimento de plantas herbáceas em solo com contaminação de metais pesados e inoculação de fungos micorrízicos arbusculares. Pesquisa agropecuária brasileira, Brasília, v. 36, n. 12, p. 1443-1452, dez. 2001.

CHANEY, R. L. Plant uptake of inorganic waste constituents. In: PARR, J. F.; MARSCH, P. B.; KLA, J. S. (Ed.). Land treatment of inorganic wastes. Park Ridge: Noyes Data, 1983. p.50-76.

CLEMENS S., PALMGREN M. G, KRAEMER U. 2002. A long way ahead: understanding and engineering plant metal accumualtion. Trends in Plant Science 7: $309-315$.

CORREIA, J. Processo de Descontaminação de Solos. In: Tecnologias do Meio Ambiente, Março-Abril, PP. 18-19. (2002).

EPA Office of Solid Waste and Emergency Response. 1997. "Recent Developments for in Situ Treatment of Metal Contaminated Soil.” Technology Innovation Office.

ERNEST, W. H. O. Bioavailability of heavy metals and decontamination of soils by plants. Applied Geochemistry, v.11, p.163-167, 1996.

FREITAS, E. V. DE S. Fitorremediação de solo contaminado por chumbo: efeitos de agentes quelantes sintéticos e naturais na dessorção, lixiviação e fitoextração. Dissertação apresentada ao Programa de Pós-Graduação em Ciência do Solo da Universidade Federal Rural de Pernambuco, como parte das exigências para obtenção do título de Mestre. Recife - PE. 2008.

GABOS, M. B. Lixiviação e absorção de chumbo pelo feijão-de-porco assistido pela aplicação de EDTA no solo. Dissertação submetida como requisito parcial para 
obtenção do grau de Mestre em Agricultura Tropical e Subtropical Área de Concentração em Gestão de Recursos Agroambientais. Campinas, SP. Abril 2008.

GONZAGA, M. I. S.; Santos, J. A. G.; Ma, L. Q. Extração de arsênio do solo por samambaias do gênero Pteris. Magistra, Cruz das Almas-BA, v. 20, n. 3, p. 291-300, jul./set., 2008.

MARQUES, D. DE A. E FERRARI, R. A. O papel das novas biotecnologias no melhoramento genético do pinhão manso. Palestra. Biológico, São Paulo, v.70, n.2, p.65-67, jul./dez., 2008.

MELO, E. E. C. DE; NASCIMENTO, C. W. A. DO; SANTOS, A. C. Q.

Solubilidade, fracionamento e fitoextração de metais pesados após aplicação de agentes quelantes. Revista Brasileira de Ciências do Solo, volume 30; pg. 1051-1060, 2006.

MOLITOR, N. (1991). Soil Wahhing. Na Overview. In: Advanced European Training Course in Soil And Groundwater Cleaning, Nov. 270 p.

NAZAROFF, W. e ALVAREZ-COHEN, L. Environmetal Enginering Science. New York. Jonh Wiley \& Sons, Inc.(2001).

OLIVEIRA, F. C.; MATTIAZZO, M. E.; Metais pesados em latossolo tratado com lodo de esgoto e em plantas de cana-de-açúcar. Scientia Agricola, v.58, n.3, p.581593, jul./set. 2001.

PEDRAZZOLI, C. D. Remediação eletrocinética de chumbo em resíduos industriais. Dissertação apresentada como requisito parcial à obtenção do grau de Mestre ao Programa de Pós-graduação em Engenharia de Materiais e Processos (PIPE), Área de Concentração de Engenharia e Ciência dos Materiais, do Setor de Tecnologia, da Universidade Federal do Paraná. Curitiba, 2004.

PENKOV, M. Basic procedures for mapping the chemical contamination of Bulgarian soils. In: MAPING OF SOIL AND TERRAIN VULNERABILITU TO SPECIFIED CHEMICAL COMPOUDS IN EUROP AT SCALE OF 1:5 M, 1991, Wageningen, Holanda. Anais. Wageningen, Holanda, 1991. P. 57-60. 
PEREIRA, B. F. F. Potencial fitorremediador das culturas de feijão de porco, girassol e milho cultivadas em Latossolo Vermelho contaminado com chumbo. 2005. $68 \mathrm{f}$. Dissertação (Mestrado) - Instituto Agronômico, Campinas, 2005.

PIRES, F. R., SOUZA, C. M., SILVA, A. A., PROCÓPIO, S. O. FERREIRA, L. R., 2003a. Fitorremediação de solos contaminados com herbicidas. Planta Daninha 21(2): 335-341.

PIRES, F. R., SOUZA, C. M., SILVA, A. A., QUEIROZ, M. E. I. R., PROCÓPIO, S. O., SANTOS, J. B., SANTOS, E. A., CECON, P. R., 2003b. Seleção de plantas com potencial de fitorremediação de Tebuthioron. Planta Daninha 21(3): 451-458.

RAMALHO, J. F. G. P.; AMARAL, N. M. B. DO; VELlOSO, A. C. X. Contaminação da microbacia de Caetés com metais pesados pelo uso de agroquímicos. Pesquisa agropecuária brasileira, Brasília, v. 35, n. 7, p. 1289-1303, jun. 2000.

ROBINSON, B.; FERNANDEZ, J. E.; MADEJÓN, P.; MARAÑHÓN, T.; MURILLO, J. M.; GREEN, S.; BRENT, C. Phyotoextraction: an assessment of biochochemical and economic viability. Plant and Soil, v.249, p.117-125, 2003.

SEPÚlVEDA, I. e RINEIRO, A. Descontaminação de Solos. In: Tecnologias do Ambiente, Janeiro, (1994) PP. 34-39.

TANDY, S.; BOSSART, K.; MUELLER, R.; RITSCHEL, J.; HAUSER, L.; SCHULIN, R.; NOWACK, B. Extraction of heavy metals from soils using biodegradable chelating agents. Environmental Science Technology, v.38, p.937944, 2004.

USEPA (2004). Guidelines for Water Reuse. Washington D.C. 